\title{
Telekontrol Hexapod Spy Robot Menggunakan WiFi Berbasis Web Server
}

\author{
Izzan Silmi Aziz ${ }^{1}$, Nur Alif Mardiyah ${ }^{2}$, Khusnul Hidayat ${ }^{3}$ \\ 1,2,3 Jurusan Teknik Elektro, Fakultas Teknik, Universitas Muhammadiyah Malang \\ izzan.abad@gmail.com
}

\begin{abstract}
Abstrak- Robot dirancang untuk membuat prototipe robot hexapod untuk daerah reruntuhan. Sistem monitoring dan control dilakukan melalui web server agar dapat mencari korban. Robot dilengkapi dengan kamera sehingga medan yang berada di depan robot dapat dilihat. Dengan algoritma PoseNet robot dapat mendeteksi wajah manusia dari berbagai arah, dengan akurasi 95,39. Gerak robot dengan algoritma Tripod Gait diimplementasikan dengan kestabilan yang cukup baik pada bidang datar. Dari aspek keamanan TLS/SSL hasil gambar dapat dikirim dapat dienkripsi untuk menghindari sniffing.
\end{abstract}

Kata kunci: PoseNet, telecontrol, IoT, hexapod, robot

\section{Pendahuluan}

Dalam hal evakuasi robot berbentuk hexapod sangat sesuai untuk membantu pencarian korban bencana alam atau reruntuhan bangunan. Robot berbentuk hexapod memiliki enam kaki yang telah banyak diriset dalam literatur untuk berbagai aplikasi termasuk eksplorasi, penyelamatan, dan pengawasan.

Contoh pengembangan penlitian robot hexapod adalah COMET-IV yang memiliki tujuan menyelesaikan misi penyelamatan [1]. Pengembangan lain yaitu robot hexapod DANTE-II yang memiliki misi ekspedisi di gunung berapi Spurr, Alaska, bertugas mengirim data, mengumpulkan data kepada operator dan para ahli gunung berapi yang berjarak 120 $\mathrm{km}$ [2]. Dan sebuah Institusi di Jepang mengembangkan robot bernama TITAN-XIII yang bertujuan melakukan hakhal umum [3].

Lalu, terdapat beberapa acuan penelitian tentang tema ini yaitu robot yang didesain pada penelitian yang sudah ada memiliki ukuran panjang sebesar $32 \mathrm{~cm}$, lebar $30 \mathrm{~cm}$ dan tinggi $25 \mathrm{~cm}$ pada saat berdiri maksimum, sedangkan pada posisi minimum (duduk) robot berukuran panjang $28 \mathrm{~cm}$, lebar $26 \mathrm{~cm}$ dan tinggi $20 \mathrm{~cm}$. Berat keseluruhan robot sebesar 2683,3 gram. Jenis motor yang digunakan adalah HS-645MG memiliki torsi maksimum $9,6 \mathrm{kgcm}$ dan rotasi yang hanya $180^{\circ}$. Ketika berjalan robot menggunakan pola tripod gait. Untuk mengontrol gerakan robot perlu mengirimkan perintah program dari PC kemudian diteruskan melalui frekuensi radio dengan modul UM96 sebagai receiver. Ini berarti tidak semua orang dapat mengendalikan robot tersebut [4].

Selanjutnya, penelitian sebelumnya dengan topik yang sama yaitu menggunakan kendali web server menggunakan mikrokomputer dan mikrokontroler. Mikrokomputer sebagai pengendali web server dan mikrokontroller sebagai pengendali servo. Untuk mengetahui objek digunakan sebuah kamera yang dikontrol menggunakan mikrokomputer. Pada penelitian ini area robot yang dilewati menggunakan kontur yang tidak rata dan pola berjalan robot menggunakan tripod gait [5].

Robot yang sudah mulai dikembangkan di Workshop Robotika Universitas Muhammadiyah Malang adalah robot berbentuk hexapod. Robot yang dikembangkan fungsi utamanya adalah mencari api. Akan tetapi robot hanya dapat berjalan sesuai dengan rute arena tertentu saja. Untuk mengetahui dinding pada ruangan dibutuhkan sensor ultrasonik yang bertujuan mengukur jarak dinding pada robot. Selanjutnya, terdapat sensor infra merah yang digunakan untuk mengetahui objek di depan robot. Aktuator yang digunakan ialah motor servo AX-18A dan Algoritma untuk pola pergerakannya menggunakan algoritma Tripod Gait [6].

Kekurangan dan kelebihan dari beberapa acuan penelitian yang sudah ada dan robot hexapod di Workshop Robotika Universitas Muhammadiyah Malang ini menjadi dasar penelitian pengembangan robot dengan memanfaatkan satu mikrokontroller yang dapat mengendalikan web server dan pergerakan robot. Selain itu kebutuhan sensor yang banyak dalam mendeteksi objek diganti dengan kamera kamera yang bertujuan memantau objek yang ada disekitar robot. Objek yang dapat dideteksi oleh robot yaitu wajah manusia. Pengembangan juga dilakukan pada pengontrol robot yaitu dengan menggunakan mikrokontroller yang memliki fitur wifi. Mikrokontroler yang digunakan bisa dijadikan sebagai akses poin yang bertujuan memudahkan pemakai dalam mengakses web server.

Untuk pergerakan robot menggunakan motor yang memiliki torsi yang tinggi dan kecepatan komunikasi yang responsif. Ketika ingin mengendalikan motor secara wireless perlu adanya software interface yang mudah digunakan oleh pemakai. Untuk mengatasi masalah tersebut maka web server sebagai alternatif memecahkan permasalahan yang ada.

Web server adalah suatu perangkat lunak dalam server yang berfungsi untuk menerima permintaan dari pengguna atau browser berupa halaman website, kemudian merespon permintaan tersebut dalam bentuk halaman website berupa dokumen HTML. Penerapan konsep web server pada pengendalian robot digunakan untuk mencapai efisiensi waktu dan pengoperasiannya mudah. Web server sangat mudah penggunaannya sehingga dapat diakses kapanpun dan dimanapun selama terkoneksi oleh satu jaringan yang sama, format penggunaan web server digunakan untuk semua platform dan memiliki dukungan interface yang stabil [7]. Pencegahan interfensi data dari luar dilakukan menggunakan tipe enkripsi TLS/SSL yang diterapkan pada web server [8]. 
Pada penelitian ini akan berfokus pada rancangan prototipe hexapod robot dengan hanya menggunakan satu mikrokontroler. Mikrokontroler juga digunakan sebagai penyedia web server untuk pengontrol robot dan memonitoring hasil pendeteksian kamera. Kemudian juga ditambahkan algoritma PoseNet sebagai mekanisme pendeteksian wajah manusia pada robot dan algoritma Tripod Gait sebagai mekanisme cara gerak robot di bidang yang datar. Robot akan dinavigasikan melalui web untuk mendeteksi manusia. Pada penelitian ini juga hanya fokus pada cara gerak robot pada bidang yang rata saja.

\section{Perancangan Sistem}

\section{A. Sistem Mekanik}

Robot hexapod adalah salah satu robot yang paling stabil secara statis dan memiliki fleksibilitas tinggi saat berdiri atau bergerak karena gerakannya menggunakan enam kaki yang dapat dengan mudah dimanipulasi.

Robot hexapod kebanyakan terinspirasi dari pergerakan hewan kecoak, serangga air atau laba-laba. Inspirasi yang digunakan merupakan contoh paling umum untuk diadopsi, telah diteliti secara etologis (studi ilmiah tentang perilaku hewan), secara neurofisiologis (studi fungsi sistem saraf), dan secara ekstensif dipelajari oleh orang lain sebelumnya. Robot hexapod mempunyai kecepatan tinggi dari pada robot quadruped saat menggunakan statically stable gait [9].

Peracangan dan pembuatan mekanik spy robot UMM terdiri dari 3 bagian yaitu kerangka utama, bentuk kaki, dan posisi kamera robot. Berikut Gambar 1 adalah desain perancangan mekanik spy robot UMM.

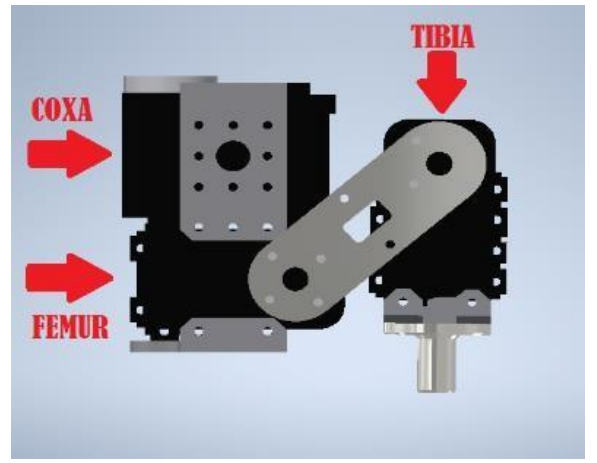

Gambar 1. Gambar kerangka bentuk kaki robot.

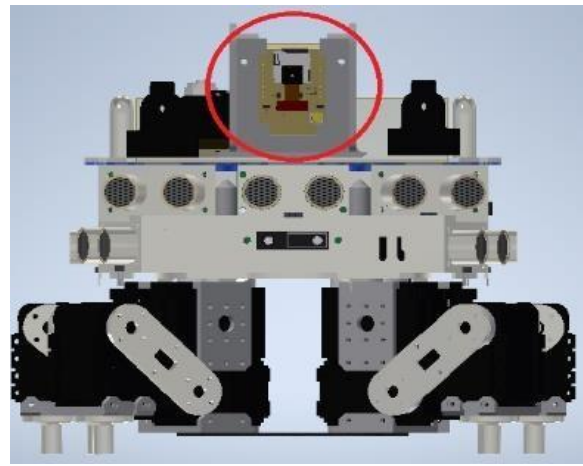

Gambar 2. Gambar kerangka bentuk posisi kamera robot
Robot dirancang dengan kerangka bentuk hexapod atau berkaki enam sehingga algoritma tripod gait dapat di terapkan. Algoritma Tripod Gait adalah algoritma gerak robot yang sering digunakan pada robot berkaki enam karena cara robot melangkah membuat robot stabil menopang sehingga pada saat berjalan robot tidak mudah tergelincir. Untuk contoh pergerakan algoritma Tripod Gait dapat dilihat pada Gambar 3.

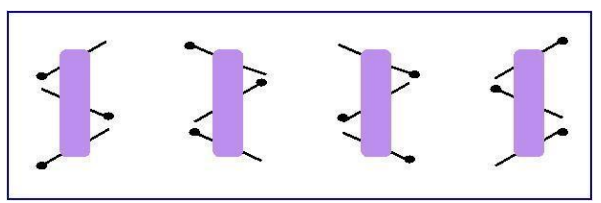

Gambar 3. Contoh pergerakan algoritma Tripod Gait

Pada Gambar 3 dapat dilihat terdapat dua langkah dalam tripod gait. Langkah pertama melibatkan tiga kaki (Kanan Depan, Kiri tengah dan Kanan belakang) menginjak tanah dan tiga kaki lainnya mengayun. Siklus yang diterapkan dilakukan secara terus menerus dan bergantian. Sehingga robot dapat bergerak maju, mundur, miring, diagonal ataupun memutar [10].

\section{B. Kinematika Robot}

Spy robot UMM yang dirancang pada penelitian kali ini memiliki 3 DOF (Degree of Freedom) yang bekerja pada sumbu $\mathrm{x}$ dan sumbu $\mathrm{y}$. Masukan yang diberikan berfungsi untuk menentukan posisi end effector pada sumbu $\mathrm{x}$ dan $\mathrm{y}$.

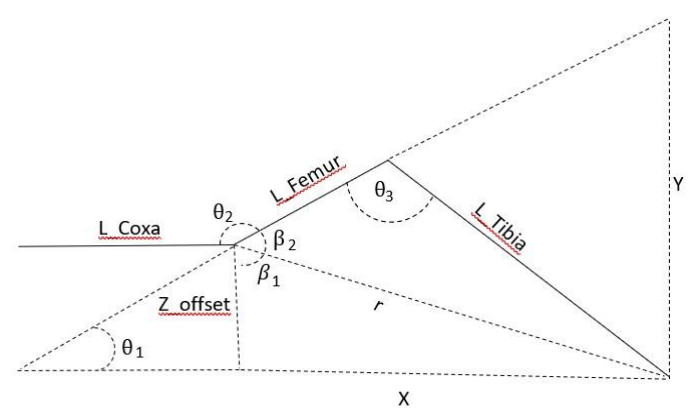

Gambar 4. Ilustrasi proyeksi samping spy robot UMM.

Pada Gambar 4 terlihat proyeksi koordinat $\mathrm{x}$ dan y pada spy robot UMM. Untuk panjang koordinat $\mathrm{x}$ dan koordinat $\mathrm{y}$ adalah nilai sebuah variabel dari posisi end effector yang telah dimasukan dalam program. Berdasarkan Gambar 4 peneliti membuat perhitungan sendiri sehingga terdapat langkahlangkah untuk membuat persamaan sebagai berikut. Langkah awal perhitungan adalah mencari nilai variabel $r$ menggunakan Persamaan (1)

$$
r=\sqrt{\left(Y-L_{\text {coxa }}\right)^{2}+Z_{\text {off set }}^{2}}
$$

Setelah nilai variabel $\mathrm{r}$ didapatkan selanjutnya mencari nilai variabel $\beta_{1}$ menggunakan Persamaan (2).

$$
\beta_{1}=\arccos \left(\frac{Z_{\text {offset }}}{r}\right)
$$


Diketahui variabel $\beta_{1}$ maka setelah itu mencari $\beta_{2}$ dengan menggunakan Persamaan (3).

$$
\beta_{2}=\arccos \left(\frac{L_{\text {Femur }}{ }^{2}+r^{2}-L_{-} \text {Tibia }^{2}}{2 x L_{\text {Femur }} x L_{\text {Tibia }}}\right)
$$

$\beta_{2}$ dan $\beta_{2}$ maka dapat diketahui

Jika sudah di dapatkan $\theta_{2}$ yang dirumuskan dalam Persamaan (4).

$$
\theta_{2}=\beta_{1}+\beta_{2}
$$

Selanjutnya untuk mencari $\theta_{3}$ menggunakan Persamaan (5).

$$
\theta_{3}=\arccos \left(\frac{L_{\text {Femur }}{ }^{2}+r^{2}-L_{-} \text {Tibia }^{2}}{2 x L_{\text {Femur }} x L_{\text {Tibia }}}\right)
$$

Setelah mengetahui nilai sudut $\theta_{3}$ maka dapat diketahui sudut $\theta_{4}$ melalui Persamaan (6).

$$
\theta_{4}=180-\theta_{3}
$$

Langkah terakhir menghitung $\theta_{1}$ Untuk menghitung $\theta_{1}$ arah proyeksi kaki harus dirubah sehingga diketahui rumus seperti Persamaan (7).

$$
\theta_{1}=\arctan \frac{X}{Y}
$$

Ketika $\theta_{1}, \theta_{2}$, dan $\theta_{4} \quad$ nilai dapat terhitung, selanjutnya nilai-nilai tersebut akan dikirim datanya ke motor servo untuk menggerakan ke enam kaki spy robot UMM.

\section{Perancangan Algoritma Gerak dan Telekontrol}

Untuk mengontrol robot secara virtual perlu adanya interfaces yang dapat mengontrol robot. Pada spy robot UMM disediakan sebuah interfaces web server yang mana membuat robot dapat dikontrol secara virtual dan dapat melihat lingkungan sekitar robot dari visualisasi modul kamera. Web server meminta request data berupa file HTML dari mikrokontroler. Apabila terkirim mikrokontroler merespon dengan memberikan data tampilan yang sesuai. Sehingga web server menampilkan hasil data kamera dan kontroler untuk menggerakan motor servo.

Komunikasi motor servo menngunakan komunikasi jenis UART. Motor servo juga memiliki alamat ID yang tidak sama setiap servo, maka dari itu pin komunikasi data servo dapat diparalel. Untuk komunikasi servo dengan mikrokontroler menggunakan komunikasi half duplex.

Sehingga diperlukan converter untuk mengubah dari komunikasi full duplex menjadi half duplex.

Untuk konfigurasi awal maka perlu di inputkan data pin servo, pin kamera, baudrate servo, ID servo, model esp32, ssid, dan password. Setelah semua terkonfigurasi dengan baik maka mikrokontroler mengirimkan data HTML.

Pengiriman data HTML menggunakan protokol HTTP. HTTP adalah protokol jaraingan pada lapisan aplikasi yang dibuat untuk memproses transfer data antara server dan klien. Protokol HTTP terdapat beberapa kumpulan perintah komunikasi. Komunikasi tersebut berlangsung antara web server dengan klien atau sebaliknya. Klien melakukam permintaan dengan mengakses alamat IP atau domain (URL).

Ketika komunikasi data berjalan dengan baik maka robot dapat dikontrol dengan web server melalui kontroler yang sudah didesain. Robot dapat dijalankan dalam berbagai arah seperti maju, mundur, belok kanan, dan belok kiri. Apabila robot terlihat akan menabrak atau terhalang oleh sebuah objek maka robot dapat diperintah untuk berhenti (stop).

Selain terdapat 3 bagian kontrol tambahan berbentuk slider pada interfaces robot yaitu Flash, ServoX, dan ServoY. Flash digunakan jika lingkungan pencahayaan pada robot kurang atau tidak ada sama sekali maka interfaces flash dapat digunakan untuk memberi penerangan tersendiri untuk robot sehingga pengelihatan robot dapat maksimal. Ketika ingin melihat beberapa sudut pandang yang tidak bisa dijangkau oleh pengelihatan robot maka dapat menggunakan interface ServoX dan ServoY. ServoX untuk mengontrol sudut pandang robot dari sisi kanan dan kiri. ServoY untuk mengontrol sudut pandang robot dari sisi atas dan bawah.

Dalam robot diberi sebuah variabel yang digunakan sebagai kode untuk mengetahui perintah navigasi dari pengguna. Variabel itu diletakkan pada program web server dan mikrokontroler. Jadi ketika pengguna menekan salah satu navigasi maka variabel itu yang dikirim sebagai kode yang akan diterjemahkan oleh mikrokontroler. Mikrokontroler akan mencocokan variabel yang dikirim, jika sudah cocok maka motor servo akan bergerak menyesuaikan perintah yang ada pada variabel itu. Berikut penjelasan mengenai cara mengontrol pergerakan spy robot UMM melalui flowchart pada Gambar 5.

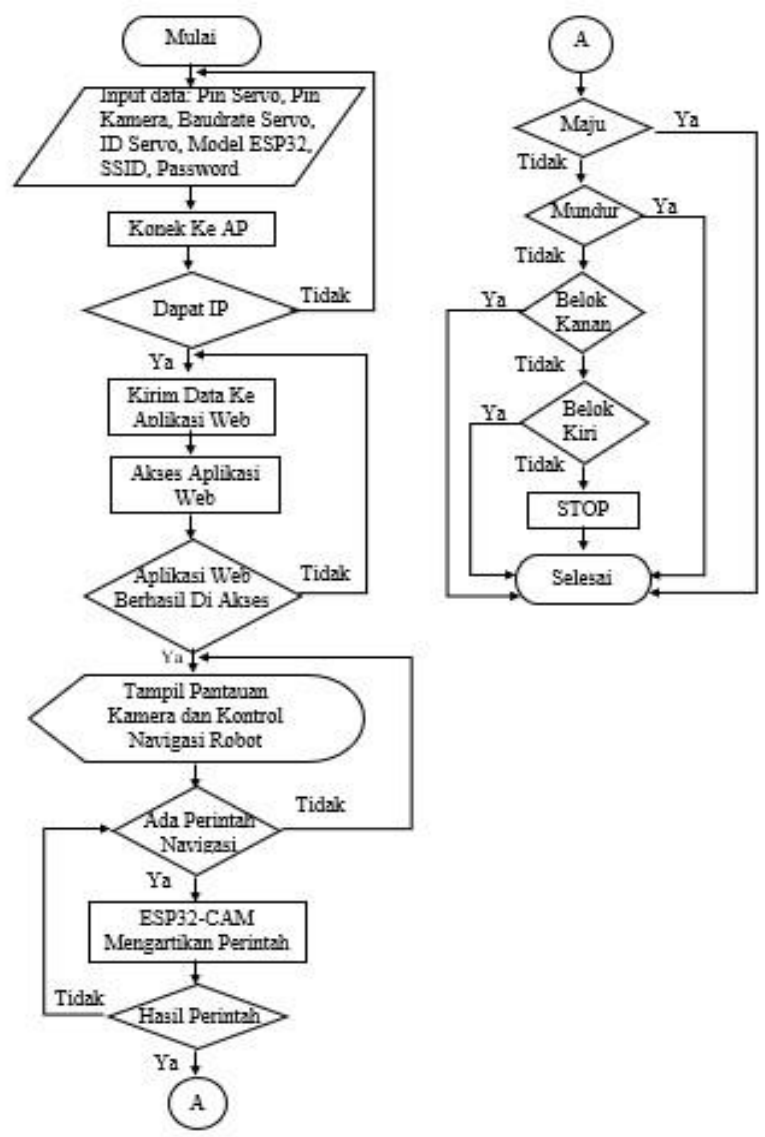

Gambar 5. Flowchart kontrol pergerakan spy robot UMM 
Rancangan pemantau pergerakan robot merupakan salah satu yang diperlukan pada pembatan spy robot UMM yang mana membutuhkan input kamera sebagai inti komponennya. Ketika mikrokontroller ESP32S-CAM mendapat sebuah alamat IP maka user akan dapat mengakses sebuah web server yang didalamnya terdapat visualisasi kamera. Visualisasi ini dirancang bertujuan agar user mengetahui objek yang ada disekitar robot. Dalam visualisasinya robot harus bisa mendeteksi wajah manusia. Wajah manusia dideteksi melalui keypoint. Keypoint itu sendiri adalah bagian dari seseorang yang sudah diestimasi, seperti hidung, mata, dan lain-lain

Berikut penjelasan mengenai cara pemantauan pergerakan spy robot UMM melalui flowchart. Flowchart terdapat pada Gambar 6.

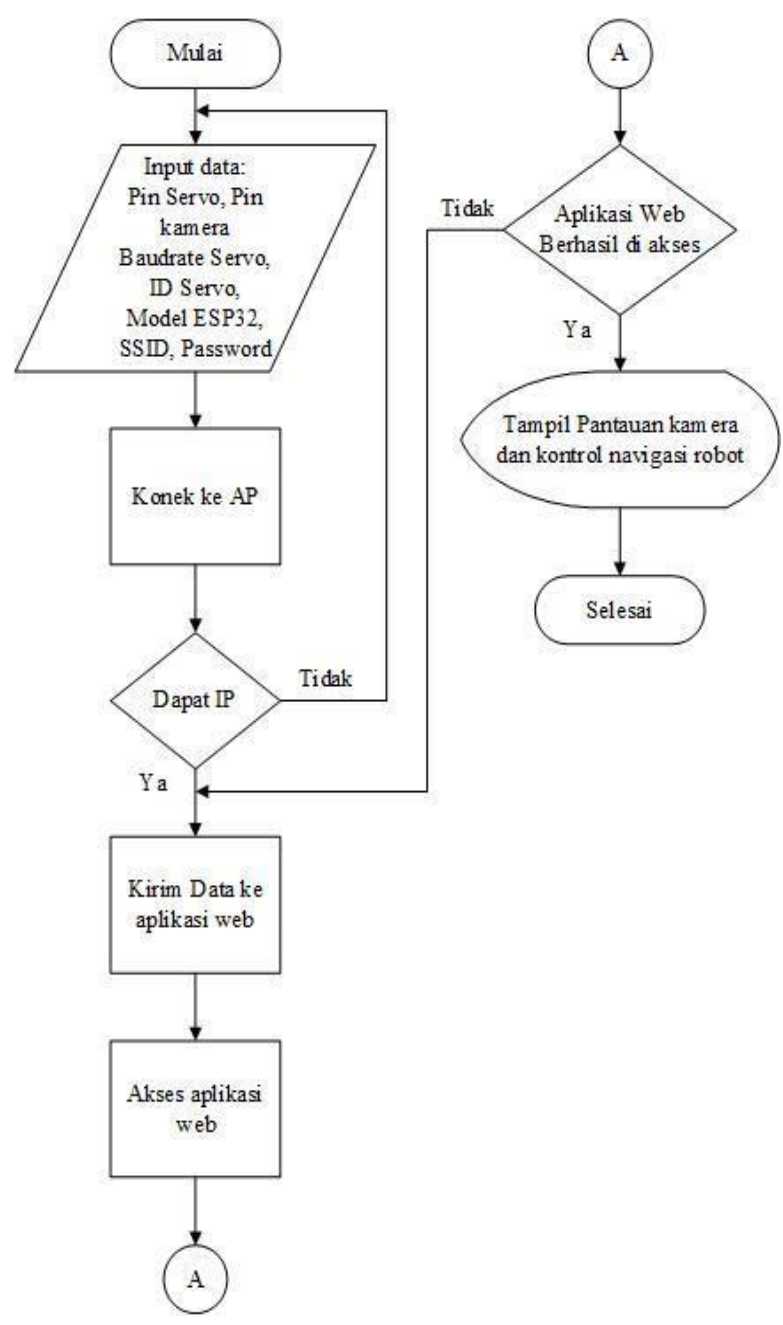

Gambar 6. Flowchart pemantauan pergerakan spy robot UMM.

\section{Perancangan Algoritma PoseNet}

SPY robot UMM merupakan robot yang dapat memvisualisasikan obejek yang dilihatnya melalui web. Akan tetapi perlu sebuah algoritma yang dapat mendeteksi sebuah objek tertentu. Salah satu algoritma yang dapat digunakan untuk mendeteksi sebuah objek adalah algoritma PoseNet. PoseNet merupakan perpaduan algoritma Resnet dan MobileNet. Resnet dipilih karena memiliki akurasi yang tinggi, Sedangkan MobileNet digunakan untuk membuat pendeteksian pose pada perangkat mobile. Algoritma ini merupakan teknik visual yang dapat membantu robot mengenali objek. Objek yang menjadi target dari spy robot UMM adalah pose wajah manusia. Dengan menggunakan algoritma ini robot dapat mendeteksi wajah manusia dari berbagai arah sudut pandang. Berikut penjelasan mengenai perancangan algoritma PoseNet pada spy robot hexapod UMM melalui flowchart. Flowchart terdapat pada Gambar 7.

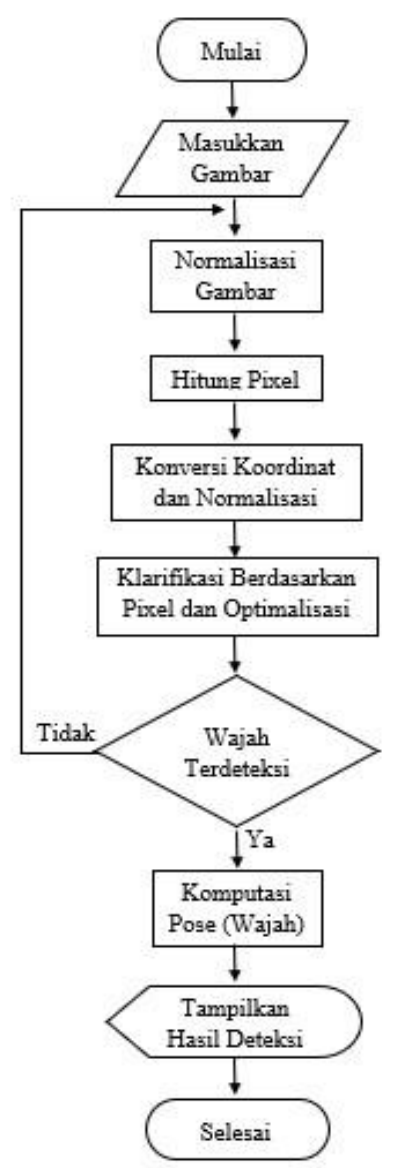

Gambar 7. Flowchart algoritma PoseNet spy robot UMM

Setelah proses pendeteksian berhasil dilakukan robot maka perlu data yang disimpan untuk hasil pendeteksiannya. Data pendeksian berupa sebuah hasil capture gambar. Ketika robot sudah mendeteksi robot maka user akan mengirim data capture dengan menekan tombol yang sudah disediakan pada web server. Hasil data capture gambar disini disimpan pada Google Drive. Dengan kapasitas yang besar Google Drive dapat menyimpan banyak hasil capture. Saat user mengirim data ke Google Drive terdapat kemanan berupa TLS/SSL yang diberikan agar terhindar dari serangan dari luar yang ingin mengambil data / merusak data. TLS/SSL (SSL) digunakan sebagai protokol kriptografi yang mengamankan komunikasi melalui jaringan komputer antara lapisan aplikasi dan lapisan pada protokol komunikasi TCP / IP. 


\section{HASIL DAN ANALISA}

Pada Gambar 8 adalah hasil pengujian algoritma Tripod Gait. Yang mana hasil grafik yang terlihat pada gambar cukup stabil ketika robot berjalan di permukaan datar dan tidak beraturan. Pada sumbu sumbu Y merupakan hasil gait dan untuk sumbu x merupakan hasil langkah dalam 1 cycle. Sesuai dengan prinsip kerjanya algoritma Tripod Gait merupakan salah satu cara robot bergerak dengan tiga kaki robot berayun dan tiga kaki berada menyentuh tanah secara bergantian yang bertujuan membuat robot berjalan.

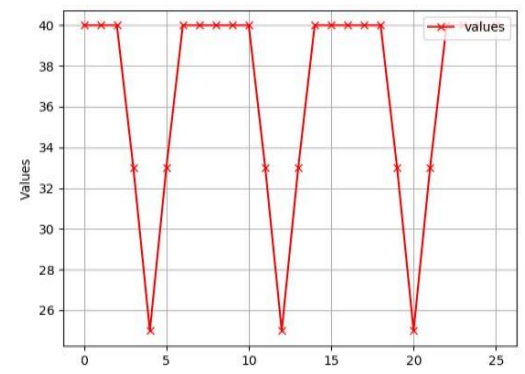

Gambar 8. Hasil pengujian algoritma Tripod Gait.

Pada Gambar 9 menunjukan hasil snapshot gerak robot menggunakan algoritma Tripod Gait, di mana robot berhasil berjalan pada bidang yang datar.
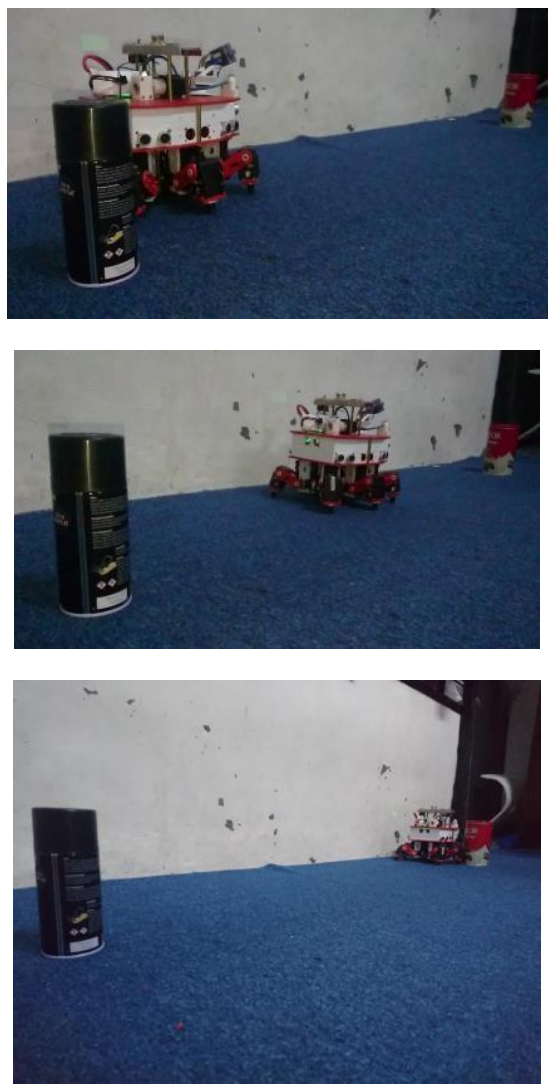

Gambar 9. Hasil pengujian pergerakan robot dengan algoritma Tripod Gait pada bidang datar.
Pada Gambar 10 menunjukan hasil snapshot gerak robot menggunakan algoritma Tripod Gait, di mana robot berhasil berjalan pada bidang yang tidak beraturan.
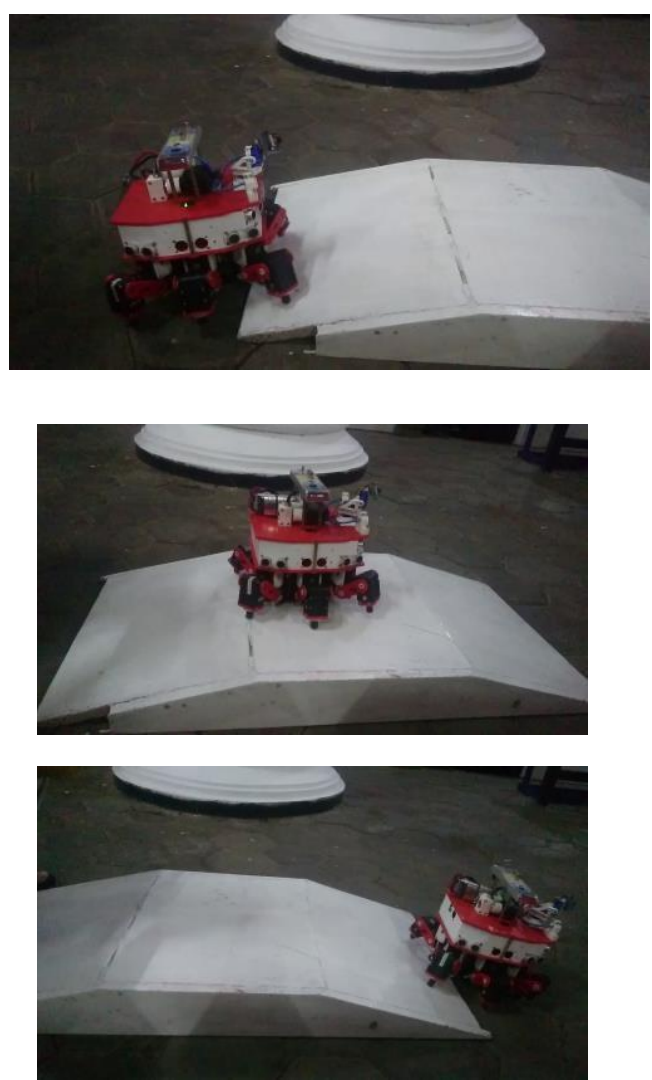

Gambar 10. Hasil pengujian pergerakan algoritma Tripod Gait pada bidang yang tidak beraturan.

Pada Gambar 11 merupakan user interfaces awal pendeteksian wajah untuk melakukan perencanaan berapa jumlah orang yang akan dideteksi.

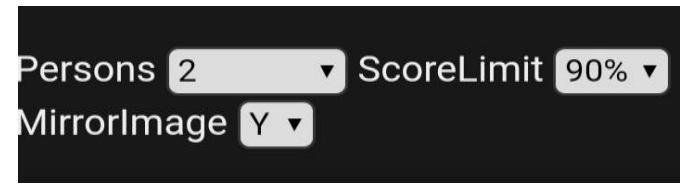

Gambar 11. Pengaturan pendeteksian wajah pada user interfaces web server

Terdapat 3 pengaturan yang dapat di rubah oleh user. Pertama Persons bertujuan untuk menentukan berapa jumlah orang yang akan dideteksi. Kedua terdapat ScoreLimit merupakan berapa titik wajah yang ingin dideteksi. Terakhir, MirrorImage untuk mengubah efek pantulan gambar sehingga cara pandang pendeteksian menjadi terbalik.

Pada Tabel 1 dan Tabel 2 berikut merupakan hasil pengukuran pendeteksian wajah manusia berdasarkan sudut pitch dan yaw. Pengujian dilakukan dengan cara mengukur jarak objek dengan robot dimulai dari $10 \mathrm{~cm}-2,5 \mathrm{~m}$ dan sudut kemiringan wajah yang di ukur mulai dari $0^{\circ}-90^{\circ}$. 
TABEL 1

PENGUKURAN PENDETEKSIAN WAJAH BERDASARKAN SUDUT YAW WAJAH

\begin{tabular}{|c|c|c|c|c|c|c|c|c|}
\hline \multirow{2}{*}{$\begin{array}{l}\text { Pengujian } \\
\text { ke- }\end{array}$} & \multirow{2}{*}{$\begin{array}{l}\text { Jarak } \\
(\mathrm{cm})\end{array}$} & \multicolumn{7}{|c|}{ Sudut Yaw Wajah $\left(^{\circ}\right)$} \\
\hline & & 0 & 15 & 30 & 45 & 60 & 75 & 90 \\
\hline 1 & 10 & $\sqrt{ }$ & $\sqrt{ }$ & $\sqrt{ }$ & $\sqrt{ }$ & $\sqrt{ }$ & $\sqrt{ }$ & $\sqrt{1}$ \\
\hline 2 & 20 & $\sqrt{ }$ & $\sqrt{ }$ & $\sqrt{ }$ & $\sqrt{ }$ & $\sqrt{ }$ & $\sqrt{ }$ & $\sqrt{ }$ \\
\hline 3 & 30 & $\sqrt{ }$ & $\sqrt{ }$ & $\sqrt{ }$ & $\sqrt{ }$ & $\sqrt{ }$ & $\sqrt{ }$ & $\sqrt{ }$ \\
\hline 4 & 40 & $\sqrt{ }$ & $\sqrt{ }$ & $\sqrt{ }$ & $\sqrt{ }$ & $\sqrt{ }$ & $\sqrt{ }$ & $\sqrt{ }$ \\
\hline 5 & 50 & $\sqrt{ }$ & $\sqrt{ }$ & $\sqrt{ }$ & $\sqrt{ }$ & $\sqrt{ }$ & $\sqrt{ }$ & $\sqrt{ }$ \\
\hline 6 & 60 & $\sqrt{ }$ & $\sqrt{ }$ & $\sqrt{ }$ & $\sqrt{ }$ & $\sqrt{ }$ & $\sqrt{ }$ & $\sqrt{ }$ \\
\hline 7 & 70 & $\sqrt{ }$ & $\sqrt{ }$ & $\sqrt{ }$ & $\sqrt{ }$ & $\sqrt{ }$ & $\sqrt{ }$ & $\sqrt{ }$ \\
\hline 8 & 80 & $\sqrt{ }$ & $\sqrt{ }$ & $\sqrt{ }$ & $\sqrt{ }$ & $\sqrt{ }$ & $\sqrt{ }$ & $\sqrt{ }$ \\
\hline 9 & 90 & $\sqrt{ }$ & $\sqrt{ }$ & $\sqrt{ }$ & $\sqrt{ }$ & $\sqrt{ }$ & $\sqrt{ }$ & $\sqrt{ }$ \\
\hline 10 & 100 & $\sqrt{ }$ & $\sqrt{ }$ & $\sqrt{ }$ & $\sqrt{ }$ & $\sqrt{ }$ & $\sqrt{ }$ & $\sqrt{ }$ \\
\hline 11 & 110 & $\sqrt{ }$ & $\sqrt{ }$ & $\sqrt{ }$ & $\sqrt{ }$ & $\sqrt{ }$ & $\sqrt{ }$ & $\sqrt{ }$ \\
\hline 12 & 120 & $\sqrt{ }$ & $\sqrt{ }$ & $\sqrt{ }$ & $\sqrt{ }$ & $\sqrt{ }$ & $\sqrt{ }$ & $\sqrt{ }$ \\
\hline 13 & 130 & $\sqrt{ }$ & $\sqrt{ }$ & $\sqrt{ }$ & $\sqrt{ }$ & $\sqrt{ }$ & $\sqrt{ }$ & $\sqrt{ }$ \\
\hline 14 & 140 & $\sqrt{ }$ & $\sqrt{ }$ & $\sqrt{ }$ & $\sqrt{ }$ & $\sqrt{ }$ & $\sqrt{ }$ & $\sqrt{ }$ \\
\hline 15 & 150 & $\sqrt{ }$ & $\sqrt{ }$ & $\sqrt{ }$ & $\sqrt{ }$ & $\sqrt{ }$ & $\sqrt{ }$ & $\sqrt{ }$ \\
\hline 16 & 160 & $\sqrt{ }$ & $\sqrt{ }$ & $\sqrt{ }$ & $\sqrt{ }$ & $\sqrt{ }$ & $\sqrt{ }$ & $\sqrt{ }$ \\
\hline 17 & 170 & $\sqrt{ }$ & $\sqrt{ }$ & $\sqrt{ }$ & $\sqrt{ }$ & $\sqrt{ }$ & $\sqrt{ }$ & $\sqrt{ }$ \\
\hline 18 & 180 & $\sqrt{ }$ & $\sqrt{ }$ & $\sqrt{ }$ & $\sqrt{ }$ & $\sqrt{ }$ & $\sqrt{ }$ & $\sqrt{ }$ \\
\hline 19 & 190 & $\sqrt{ }$ & $\sqrt{ }$ & $\sqrt{ }$ & $\sqrt{ }$ & $\sqrt{ }$ & $\sqrt{ }$ & $\sqrt{ }$ \\
\hline 20 & 200 & $\sqrt{ }$ & $\sqrt{ }$ & $\sqrt{ }$ & $\sqrt{ }$ & $\sqrt{ }$ & $\sqrt{ }$ & $\sqrt{ }$ \\
\hline 21 & 210 & $\sqrt{ }$ & $\sqrt{ }$ & $\sqrt{ }$ & $\sqrt{ }$ & $\sqrt{ }$ & $\sqrt{ }$ & $\sqrt{ }$ \\
\hline 22 & 220 & $\sqrt{ }$ & $\sqrt{ }$ & $\sqrt{ }$ & $\sqrt{ }$ & $\sqrt{ }$ & $\sqrt{ }$ & $\sqrt{ }$ \\
\hline 23 & 230 & $\sqrt{ }$ & $\sqrt{ }$ & $\sqrt{ }$ & $\sqrt{ }$ & $\sqrt{ }$ & $\sqrt{ }$ & $\sqrt{ }$ \\
\hline 24 & 240 & $\sqrt{ }$ & $\sqrt{ }$ & $\sqrt{ }$ & $\sqrt{ }$ & $\sqrt{ }$ & $\sqrt{ }$ & $\sqrt{ }$ \\
\hline 25 & 250 & $\sqrt{ }$ & $\sqrt{ }$ & $\sqrt{ }$ & $\sqrt{ }$ & $\sqrt{ }$ & $\sqrt{ }$ & $\sqrt{ }$ \\
\hline
\end{tabular}

TABEL 2

PENGUKURAN PENDETEKSIAN WAJAH BERDASARKAN SUDUT PITCH WAJAH

\begin{tabular}{|c|c|c|c|c|c|c|c|}
\hline \multirow{2}{*}{$\begin{array}{l}\text { Pengujian } \\
\text { ke- }\end{array}$} & \multirow{2}{*}{$\begin{array}{r}\text { Jarak } \\
(\mathrm{cm}) \\
\end{array}$} & \multicolumn{6}{|c|}{ Sudut Pitch Wajah $\left({ }^{\circ}\right)$} \\
\hline & & 15 & 30 & 45 & 60 & 75 & 90 \\
\hline 1 & 10 & $\sqrt{ }$ & $\sqrt{ }$ & $\sqrt{ }$ & $\sqrt{ }$ & $\sqrt{ }$ & $\sqrt{ }$ \\
\hline 2 & 20 & $\sqrt{ }$ & $\sqrt{ }$ & $\sqrt{ }$ & $\sqrt{ }$ & $\sqrt{ }$ & $\sqrt{ }$ \\
\hline 3 & 30 & $\sqrt{ }$ & $\sqrt{ }$ & $\sqrt{ }$ & $\sqrt{ }$ & $\sqrt{ }$ & $\sqrt{ }$ \\
\hline 4 & 40 & $\sqrt{ }$ & $\sqrt{ }$ & $\sqrt{ }$ & $\sqrt{ }$ & $\sqrt{ }$ & $\sqrt{ }$ \\
\hline 5 & 50 & $\sqrt{ }$ & $\sqrt{ }$ & $\sqrt{ }$ & $\sqrt{ }$ & $\sqrt{ }$ & $\sqrt{ }$ \\
\hline 6 & 60 & $\sqrt{ }$ & $\sqrt{ }$ & $\sqrt{ }$ & $\sqrt{ }$ & $\sqrt{ }$ & $\sqrt{ }$ \\
\hline 7 & 70 & $\sqrt{ }$ & $\sqrt{ }$ & $\sqrt{ }$ & $\sqrt{ }$ & $\sqrt{ }$ & $\sqrt{ }$ \\
\hline 8 & 80 & $\sqrt{ }$ & $\sqrt{ }$ & $\sqrt{ }$ & $\sqrt{ }$ & $\sqrt{ }$ & $\sqrt{ }$ \\
\hline 9 & 90 & $\sqrt{ }$ & $\sqrt{ }$ & $\sqrt{ }$ & $\sqrt{ }$ & $\sqrt{ }$ & $\sqrt{ }$ \\
\hline 10 & 100 & $\sqrt{ }$ & $\sqrt{ }$ & $\sqrt{ }$ & $\sqrt{ }$ & $\sqrt{ }$ & $\sqrt{ }$ \\
\hline 11 & 110 & $\sqrt{ }$ & $\sqrt{ }$ & $\sqrt{ }$ & $\sqrt{ }$ & $\sqrt{ }$ & $\sqrt{ }$ \\
\hline 12 & 120 & $\sqrt{ }$ & $\sqrt{ }$ & $\sqrt{ }$ & $\sqrt{ }$ & $\sqrt{ }$ & $\sqrt{ }$ \\
\hline 13 & 130 & $\sqrt{ }$ & $\sqrt{ }$ & $\sqrt{ }$ & $\sqrt{ }$ & $\sqrt{ }$ & $\sqrt{ }$ \\
\hline 14 & 140 & $\sqrt{ }$ & $\sqrt{ }$ & $\sqrt{ }$ & $\sqrt{ }$ & $\sqrt{ }$ & $\sqrt{ }$ \\
\hline 15 & 150 & $\sqrt{ }$ & $\sqrt{ }$ & $\sqrt{ }$ & $\sqrt{ }$ & $\sqrt{ }$ & $\sqrt{ }$ \\
\hline 16 & 160 & $\sqrt{ }$ & $\sqrt{ }$ & $\sqrt{ }$ & $\sqrt{ }$ & $\sqrt{ }$ & $\sqrt{ }$ \\
\hline 17 & 170 & $\sqrt{ }$ & $\sqrt{ }$ & $\sqrt{ }$ & $\sqrt{ }$ & $\sqrt{ }$ & $\sqrt{ }$ \\
\hline 18 & 180 & $\sqrt{ }$ & $\sqrt{ }$ & $\sqrt{ }$ & $\sqrt{ }$ & $\sqrt{ }$ & $\sqrt{ }$ \\
\hline 19 & 190 & $\sqrt{ }$ & $\sqrt{ }$ & $\sqrt{ }$ & $\sqrt{ }$ & $\sqrt{ }$ & $\sqrt{ }$ \\
\hline 20 & 200 & $\sqrt{ }$ & $\sqrt{ }$ & $\sqrt{ }$ & $\sqrt{ }$ & $\sqrt{ }$ & $\sqrt{ }$ \\
\hline 21 & 210 & $\sqrt{ }$ & $\sqrt{ }$ & $\sqrt{ }$ & $X$ & $X$ & $X$ \\
\hline 22 & 220 & $\sqrt{ }$ & $\sqrt{ }$ & $\sqrt{ }$ & $X$ & $X$ & X \\
\hline 23 & 230 & $\sqrt{ }$ & $\sqrt{ }$ & $\sqrt{ }$ & $X$ & $X$ & $X$ \\
\hline 24 & 240 & $\sqrt{ }$ & $\sqrt{ }$ & $\sqrt{ }$ & $X$ & $X$ & $X$ \\
\hline 25 & 250 & $\sqrt{ }$ & $\sqrt{ }$ & $\sqrt{ }$ & $X$ & $X$ & X \\
\hline
\end{tabular}

Hasil pengujian tersebut menunjukkan bahwa algoritma yang diterapkan agar dapat mendeteksi wajah dengan berbagai arah berhasil.

Tujuan dari pendeteksian wajah adalah agar robot dapat membedakan antara manusia dengan objek yang lain. Setelah korban terdeteksi oleh robot maka operator web server akan mengambil gambar seperti pada Gambar 12 dan Gambar 13 sebagai data untuk tim SAR sehingga lebih mudah mengindentifikasi ada korban manusia.

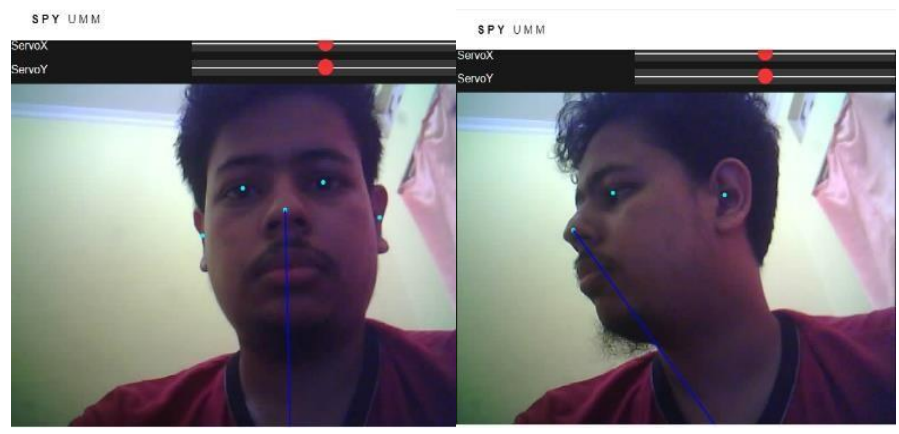

Gambar 12. Hasil pengujian algoritma PoseNet untuk satu orang dengan wajah ke arah depan dan wajah ke arah kanan.

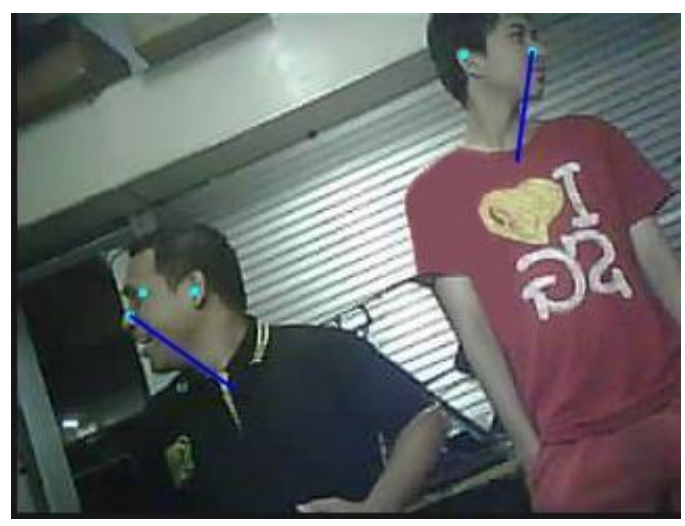

Gambar 13. Hasil pengujian algoritma PoseNet lebih dari satu dengan pendeteksian wajah berlawanan arah.

Pada Gambar 14 adalah hasil pengujian keamanan TLS/SSL. Dapat dianalisa bahwa pengiriman data gambar dari hasil capture web server dapat di enkripsi menggunakan protokol TLS/SSL sehingga data dapat dicegah apabila terdapat sniffing. 


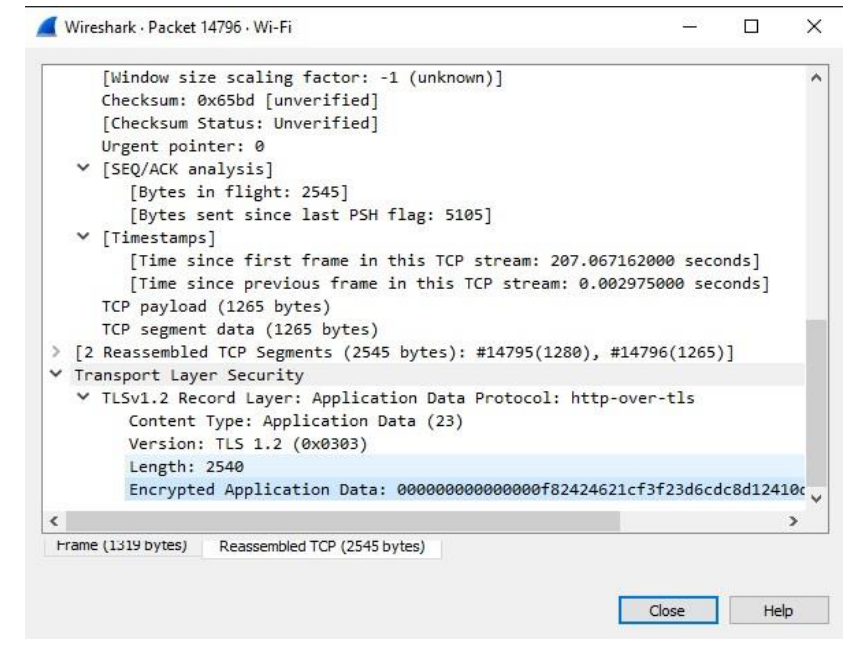

Gambar 14. Hasil pengujian keamanan pengiriman gambar menggunakan protokol TLS/SSL.

\section{KESIMPULAN}

Pada makalah ini robot hexapod spy telah dikembangkan dengan mekanisme gerak menggunakan Tripod Gait dan telekontrol menggunakan wifi. Selain itu deteksi objek manusia melalui wajah juga telah dilakukan dengan PoseNet. Keamanan data pengiriman terjamin melalui enkripsi data dengan protokol TLS/SSL.

Mekanisme kerja sistem pemantauan dan kontrol pergerakan robot hexapod spy UMM berjalan sesuai dengan sistem yang efeektif dan tepat guna karena robot dapat dikontrol oleh user melalui web server dan robot dapat mendeteksi wajah manusia. Pendeteksian yang menggunakan algoritma PoseNet dapat membantu robot dalam mendeteksi wajah dari berbagai arah.

Desain mekanik robot yang sesuai dengan sistem pemantauan dan kontrol pergerakan robot hexapod spy UMM memudahkan untuk dibawa ke mana-mana. Desain hardware robot yang mendukung sistem pemantauan dan kontrol pergerakan robot hexapod SPY UMM sehingga membuat sistem bekerja sesuai perancangan sistem.

Pada pengiriman gambar melalui web server, robot juga memiliki keamanan ketika melakukannya. Tersedianya protokol TLS/SSL pada robot memungkinkan robot dapat mengirimkan hasil gambar ke Google Drive dengan aman, terutama pada kasus sniffing.

\section{UCAPAN TERIMA KASIH}

Ucapan terima kasih kepada LSO Workshop Robotika Universitas Muhammadiyah Malang, yang selama proses penelitian memberikan fasilitas pendukung sehingga pengambilan data berjalan dengan baik.

\section{REFERENSI}

[1] K. Nonami, R. K. Barai, A. Irawan, and M. R. Daud, Hydraulically Actuated Hexapod Robots, Springer, vol. 66. 2014.

[2] J. E. Bares and D. S. Wettergreen, "Dante II: technical description, results, and lessons learned," Int. J. Rob. Res., vol. 18, no. 7, pp. 621649, 1999.

[3] S. Kitano, S. Hirose, G. Endo, and E. F. Fukushima, "Development of lightweight sprawling-type quadruped robot TITAN-XIII and its dynamic walking," IEEE Int. Conf. Intell. Robot. Syst., pp. 6025-6030, 2013.

[4] D. Harsono, B. Suhendro, and R. Laksono, Rancang Bangun Robot Hexapod dengan Kendali Jarak Jauh, STTN-BTNN, 2012.

[5] I. C. Mauko and S. Tunliu, "Kontrol arah gerak web kamera (webcam) berbasis web," J. Ilm. Flash, vol. 2, no. 2, p. 106, 2019.

[6] K. Hidayat, "Perancangan robot hexapod pemadam api pada Kontes Robot Cerdas Indonesia 2011," Skripsi, University of Muhammadiyah Malang, 2012.

[7] A. Amir and M. Nur Faisal, "Perancangan dan penerapan sistem kontrol peralatan elektronik jarak jauh berbasis web," J. Mek., vol. 6, no. 2, pp. 577-584, 2015.

[8] C. Liu, J. Han, and Q. Wei, Browser Identification Based on Encrypted Traffic. 2016.

[9] M. Ahmed, M. R., M. Billah, and S. Farh, "Walking hexapod robot in disaster recovery: developing algorithm for terrain negotiation and navigation," New Adv. Technol., vol. 2, no. 6, pp. 795-800, 2010.

[10] A. Chairunnas, "Penerapan algoritma Tripod Gait pada robot hexapod menggunakan Arduino Mega 128," Jurnal Penelitian Pos dan Informatika vol. 7, no. 1, pp. 37-48, 2017. 